\title{
Häufig benutzte Einheiten
}

a) Vielfache und Teile von Einheiten
k Kilo (103)
$m$ milli $\left(10^{-3}\right)$
M Mega $\left(10^{6}\right)$
$\mu$ mikro $\left(10^{-6}\right)$
G Giga $\left(10^{2}\right)$
$n$ nano $\left(10^{-9}\right)$
T Tera (10 12 )
$\mathrm{p}$ pico $\left(10^{-12}\right)$

b) Grundeinheiten

$\begin{array}{ll}\text { m } & \text { Meter } \\ \text { g } & \text { Gramm } \\ \text { sec } & \text { Sekunde }\end{array}$

c) Masseeinheiten

Mol Molekulargewicht (Molekülmasse) in Gramm (Masse von 6,023 • $10^{23}$ Molekülen).

Val Äquivalentgewicht in Gramm, Grammäquivalent (= Mol/Wertigkeit, Ionenmasse mit insgesamt $6,023 \cdot 10^{23}$ Valenzen).

g-Atom Atomgewicht (Atommasse) in Gramm, Grammatom (Masse von $6,023 \cdot 10^{23}$ Atomen.

Osm Osmol, Masse von $6,023 \cdot 10^{23}$ gelösten osmotisch wirksamen Teilchen, identisch mit Mol, wenn keine Dissoziation in Lösung vorliegt.

l Liter, ein $\mathrm{kg}$ Wasser der Dichte bei 3,98 $\mathrm{C}$ und 760 Torr.

d) Konzentrationseinheiten

M Eine Lösung, die ein Mol eines gelösten Stoffes $/ 1000 \mathrm{~m} l$ Gesamtlösung enthält, wird als 1 molare Lösung (M) bezeichnet. 
$\mathrm{N} \quad$ Eine Lösung, die ein Val eines gelösten Stoffes $/ 1000 \mathrm{~m} l$ Gesamtlösung enthält, wird als 1 normale Lösung (N) bezeichnet.

$\mathrm{mg} / 100 \mathrm{~g} \mathrm{mg}$ des gelösten Stoffes in $100 \mathrm{~g}$ Gesamtlösung. Bei Angabe für Organe oder Gewebe wird das Frischgewicht oder Trockengewicht des Organs mit dem Gewicht der Gesamtlösung gleichgesetzt.

$\mathrm{mg} / 100 \mathrm{~m} / \mathrm{mg}$ des gelösten Stoffes in $100 \mathrm{~m} /$ Gesamtlösung (z. B. Blut, Plasma, Serum, Harn). 